\title{
Current understanding of chronic total occlusion of the internal carotid artery (Review)
}

\author{
BAOFENG XU ${ }^{1}, \mathrm{CHAO} \mathrm{LI}^{2}, \mathrm{YUNBAO} \mathrm{GUO}^{1}, \mathrm{KAN} \mathrm{XU}^{1}, \mathrm{YI} \mathrm{YANG}^{2}$ and JINLU YU ${ }^{1}$ \\ Departments of ${ }^{1}$ Neurosurgery and ${ }^{2}$ Neurology, The First Hospital of Jilin University, Changchun, Jilin 130021, P.R. China
}

Received November 29, 2017; Accepted December 12, 2017

DOI: $10.3892 /$ br.2017.1033

\begin{abstract}
At present, there is limited understanding of chronic total occlusion (CTO) of the internal carotid artery (ICA). Therefore, the present report collected related cases from PubMed and reviewed the literature. Cerebral vessels may form collateral circulation immediately or gradually following CTO of the ICA. The natural history of CTO of the ICA includes a variety of outcomes, all of which are biased toward a non-benign progressive process and are characterized by insufficient cerebral perfusion, embolus detachment and cognitive dysfunction. The majority of cases of CTO of the ICA require treatment. In early studies, the results of external-ICA bypass were unsatisfactory, while recanalization is now considered the only viable option. The current treatment indications mainly depend on the degree of injury to the cerebrovascular reserve and the extent to which the oxygen extraction fraction is increased. The length, height and duration of ICA occlusion are also relevant, though more frequently, the condition depends on multiple factors. Endovascular interventional recanalization, carotid endarterectomy (CEA) and hybrid surgery may be conducted in a select group of patients. As novel materials are developed, the success rate of simple recanalization may gradually increase; however, hybrid surgery may be more representative of the current trend, as advanced CEA can remove carotid atherosclerosis plaques, thus reducing the technological demands of the subsequent interventional recanalization. There are many complications that may result from recanalization following CTO of the ICA, including hyperperfusion and technical errors; therefore, the operation must be conducted carefully. If the recanalization
\end{abstract}

Correspondence to: Professor Jinlu Yu, Department of Neurosurgery, The First Hospital of Jilin University, 71 Xinmin Avenue, Changchun, Jilin 130021, P.R. China

E-mail: jinluyu@hotmail.com

Professor Yi Yang, Department of Neurology, The First Hospital of Jilin University, 71 Xinmin Avenue, Changchun, Jilin 130021, P.R. China

E-mail: doctoryangyi@163.com

Key words: internal carotid artery, occlusion, chronic, recanalization, review is successful, it typically results in a stable improvement of patient condition in the long term. However, despite these conclusions, more studies are required in the future to further improve current understanding of CTO of the ICA.

\author{
Contents \\ 1. Introduction \\ 2. Natural history of the disorder \\ 3. Hemodynamics \\ 4. Pathogenesis \\ 5. Clinical manifestations \\ 6. Imaging \\ 7. Indications for surgical treatment \\ 8. Treatments \\ 9. Factors affecting recanalization \\ 10. Complications of treatment \\ 11. Prognosis \\ 12. Conclusion
}

\section{Introduction}

Internal carotid artery (ICA) occlusion has an incidence rate of approximately 6 per 100,000 individuals and may account for $15,000-20,000$ ischemic events in the United States $(1,2)$. In China, though there are no clear incidence statistics, the estimated incidence rate is substantial (3). Certain cases of ICA occlusion are chronic; however, the minimum duration that constitutes 'chronic' ICA occlusion is yet to be comprehensively defined. A previous study, based on circumstantial clinical and radiological imaging data, defined chronic occlusion as occlusion lasting more than 4 weeks (5). Chronic occlusion may be distinguished from acute occlusion by computed tomography (CT) angiography (CTA), as the 'carotid ring sign' (defined as the presence of hypodensity in the ICA and/or contrast within the carotid wall) is visible in CTA of acute ICA occlusion (4). Another study suggested, according to current data in the field of cardiovascular medicine, that the minimum threshold for chronic total occlusion (CTO) of the ICA should be at least 3 months, and possibly even more than six months (5).

At present, it is considered that surgical treatment is indicated for CTO of the ICA if pharmacotherapy therapy fails or as prophylaxis treatment in high-risk patients (6). There 
are a number of treatments for CTO of the ICA. The Carotid Occlusion Surgery Study (COSS) randomized trial in 2011 was the earliest comparison of surgical ICA treatments, though external carotid-internal carotid bypass surgery has ultimately been demonstrated to be ineffective $(7,8)$. Nevertheless, CTO of the ICA necessitates recanalization. Certain patients may develop cerebral infarction due to insufficient collateral compensation or embolus detachment (9). Furthermore, certain cases of CTO of the ICA may develop insidiously without a clear neurological event; these 'clinically silent' occlusions may eventually result in critical consequences $(10,11)$.

In recent years, surgeons have treated CTO of the ICA using recanalization methods, including carotid endarterectomy (CEA) and endovascular treatment. As these techniques are relatively immature, the risks of the intervention are typically greater than the benefits, and the curative effects are not ideal. However, the development of these techniques and the emergence of hybrid surgery in recent years has provided novel options for treating CTO of the ICA, and the success rate has gradually improved (12). Nonetheless, controversy regarding appropriate therapeutic approaches for CTO of the ICA remains to be an issue. Therefore, the current report reviewed the available literature published prior to December 6th, 2017. 'Chronic occlusion of carotid artery' was used as a search term in the PubMed (https://www.ncbi.nlm.nih.gov/pubmed) and Web of Science (www.isiknowledge.com) databases to identify English-language publications. More than 300 articles were obtained, 119 of which are cited here. Overall, this report aimed to review the literature and propose hypotheses based on the available literature and personal experience, in order to establish an improved understanding of CTO of the ICA.

\section{Natural history of the disorder}

The natural history of CTO of the ICA is yet to be fully determined, though may be divided into the following categories according to outcome:

i) In cases of sufficient collateral compensation, there is no impairment in the cerebrovascular reserve (CVR). The CTO may remain in a stable state, particularly in non-symptomatic cases (13). An occluded ICA is considered a 'safe artery' as it causes few symptoms following optimal medical management; the recurrence rate for symptoms in the region is relatively low at $2-8 \%$ annually (14).

ii) In cases of insufficient collateral compensation, the CVR is damaged. CTO of the ICA may lead to new, continuous hypoperfusion infarcts on the occlusion side of the brain tissue, with the infarcts readily developing in the middle cerebral artery-anterior cerebral artery watershed territory; in this case, the risk of ischemic symptoms may be as high as $30 \%$ per year (15).

iii) In cases of effective collateral circulation compensation accompanied by emboli from a narrow common or external carotid artery, emboli from a proximal or distal ICA stump or emboli from a diseased contralateral artery, which eventually enter the collateral circulation and cerebral hypoperfusion area (16), the patients are at risk of recurrent ipsilateral neurological events even following optimal medical management.

iv) In rare cases, a small but marked proportion of CTO of ICA may recanalize over time, even after more than 3 months of blockage (17). In a study by Morris-Stiff et al (18), the rate of recanalization was approximately $10 \%$, and in previous studies, the rate was $2.3 \%(18-21)$. This spontaneous recanalization may increase blood flow to the diseased side of the brain, though may also lead to an increased risk of stroke (22). The primary reason for this increased risk is that pathological recanalization is typically associated with stenosis of the carotid artery, which increases the probability of embolus detachment (14). Therefore, further treatment is needed to prevent embolus detachment following recanalization (23).

\section{Hemodynamics}

In CTO of the ICA, hemodynamics may be normal or impaired, depending on the recruitment of cerebral collaterals (24). Collateral circulation in the brain is among the most influential factors in mediating the potentially critical effects of cerebral ischemia $(25,26)$.

Macroscopic blood flow compensation. Following CTO of the ICA, perfusion pressure at the vascular occlusion is decreased (27). In response to the deficient blood supply from main arteries, the cerebral blood flow (CBF) immediately establishes collateral circulation; this involves immediate diversion of blood flow in the event of large-vessel occlusion, as well as chronic compensation by secondary collaterals such as the ipsilateral ophthalmic artery, ipsilateral posterior communicating artery, anterior communicating artery and pia mater collaterals (28). Effective leptomeningeal collateral circulation and the presence of more than 2 collaterals have been associated with good clinical condition without severe disability (28).

Changes in microscopic brain blood flow. CVR, a key function of the cerebral vasculature, is defined as the increase in $\mathrm{CBF}$ in response to a vasodilatory stimulus (29). In CTO of the ICA, CVR is reduced; this impairment has been associated with increased risk of ischemic events and may be useful for stroke risk stratification (30). In normal cases, CVR is unimpaired (stage 0) (31). CVR impairment may be divided into three stages: In stage I hemodynamic failure, autoregulatory compensatory vasodilation is still able to maintain normal $\mathrm{CBF}$, and the oxygen extraction fraction (OEF) remains normal. In stage II hemodynamic failure, also known as misery perfusion, autoregulatory compensation is exhausted and $\mathrm{CBF}$ is reduced; however, cerebral metabolic compensation occurs through an increased OEF from the delivered blood supply. In stage III hemodynamic failure, both $\mathrm{CBF}$ and $\mathrm{OEF}$ are reduced to the point of ischemia and ultimately infarction (32-34).

\section{Pathogenesis}

CTO of the ICA may be caused by numerous factors. In younger patients, it is often due to chronic dissection occlusion of the carotid artery, invariably terminating at the entrance to the petrous region of the vessel, while in older patients, the occlusion is often caused by atherosclerosis, which mainly develops in the proximal portion of the ICA as a result of the complex hemodynamics of low shear stress, flow stasis and flow separation at this site (35). Complete occlusion of 
the ICA by atherosclerotic disease causes approximately $15-25 \%$ of ischemic strokes in patients with carotid artery blockage (36). The majority of CTO cases treated in the First Hospital of Jilin University (Changchun, China) are caused by arteriosclerosis, with harder or calcified atherosclerosis plaques presenting difficulties for recanalization. In addition, radiotherapy may also cause chronic occlusion of the carotid artery. Nico et al (37) reported a patient who developed chronic carotid artery occlusion following a history of neck irradiation for an oropharyngeal undifferentiated carcinoma.

\section{Clinical manifestations}

CTO of the ICA may be asymptomatic or cause fluctuating clinical symptoms, including recurrent transient ischemic attack or minor/major stroke, which depend on the patient's collateral circulation and cerebral vasoreactivity associated with hemodynamic factors (38).

No clinical symptoms. In certain cases of CTO of the ICA, effective compensatory collateral circulation provides sufficient arterial blood to meet the needs of the brain (39). These cases with a low degree of cerebral hemodynamic compromise, as well as some stage I cases with effective CVR function, may have a benign prognosis (40).

Inadequate brain infusion. Certain cases of CTO of the ICA with poor compensatory collateral circulation may present ischemic symptoms (41). Cerebral ischemia reflects a deficiency of collateral flow that is blood pressure dependent, and may lead to a hemodynamic infarction pattern (42). Reversible low perfusion is often characterized by recurrent transient ischemic attack, while severe ischemia presents as minor/major stroke (43).

Embolus detachment. Some CTOs of the ICA are accompanied by full hemodynamic compensation, though nonetheless continuously produce cerebral infarcts (44). The emboli primarily originate from a narrow common or external carotid artery, from a proximal or distal ICA stump or from a diseased contralateral artery $(16,44)$.

Cognitive function impairment. CTO of the ICA may be characterized solely by impairments in cognitive function, including declines in psychomotor speed, executive function and working memory $(45,46)$. In these patients, chronic neuronal damage may be identified in the cerebral white matter, as indicated by reduced N-acetyl aspartate concentration (47). These pathological findings affect not only the ipsilateral but also the contralateral hemisphere (48). Successful treatment of CTO of the ICA may improve global cognitive function as well as attention and psychomotor processing speed (49-51).

\section{Imaging}

In the past 20 years, there has been considerable progress in imaging techniques, which has enabled physicians to identify conditions including hemodynamic ischemia and poor collateral circulation as well as patients at high risk of recurrent stroke (52).
Examination of morphology and bloodflow. Regarding general examination of CTO of the ICA, a CT scan or magnetic resonance imaging (MRI) should first be performed to determine the presence of hemorrhage or infarction. At the same time, perfusion CT and perfusion MRI should be conducted to assess for the occurrence and severity of cerebral ischemia $(53,54)$. Perfusion CT or MRI often identifies perfusion-diffusion mismatch, characterized by a severe delay of brain perfusion in the ICA territory accompanied by a normal regional cerebral blood volume and no change in diffusion-weighted imaging (55). The delay of perfusion may be substantial, for example, $6 \mathrm{sec}$ or more, with respect to the unaffected cerebral hemisphere $(24,56)$. In addition, single-photon emission CT and xenon-enhanced $\mathrm{CT}$ are also effective tools for evaluating brain blood flow (57).

CTA, magnetic resonance angiography, digital subtraction angiography and ultrasound should also be undertaken concurrently (58). These examinations can directly measure the length of the occluded artery, the degree of reverse filling by the distal blood flow of the occluded artery, the shape of the ICA residue at the occlusion and the degree of compensation by the collateral circulation, among other features (59). In addition, a high-resolution MRI examination may be conducted to image the occluded carotid artery extensively, to provide more detailed information on the arterial occlusion (60). Quantitative MRI may also aid to demonstrate the difference in the degree of primary collateral flow in cases of ICA occlusion (61).

Examination of the CVR. CVR is a crucial diagnostic tool when evaluating CTO of the ICA. This variable has been identified as a predictor of ischemic stroke (62). CVR may be calculated according to the following formula: CVR $=($ CBFstimulated - CBFrest $) /$ CBFrest $x 100 \%$. Transcranial Doppler studies are often used to assess vasoreactivity, and have suggested that in patients with CTO of the ICA, a breath-holding index of $<0.69$ is correlated with a high risk of subsequent stroke $(63,64)$.

In addition, CVR may be measured by perfusion CT or MRI with inhalation of $8 \% \mathrm{CO}_{2}$ or injection of acetazolamide, with CVR impairment distinguished using a $10 \%$ cut-off point. If CVR is less than $10 \%$, the risk of cerebral infarction is elevated $(65,66)$. Certain novel MRI imaging modalities may also be used to examine CVR, including blood oxygenation level-dependent (BOLD) MRI or acetazolamide-augmented dynamic BOLD imaging $(48,67)$.

$O E F$. OEF is important in the examination of CTO of the ICA and is considered to provide the strongest indication of the need for recanalization surgery (68). Positron emission tomography (PET) is the gold standard for measuring OEF (69-72). The OEF ratio is calculated based on measurements on the diseased and healthy sides. When the OEF ratio exceeds a certain level, cerebrovascular recanalization is required. The treatment standard is defined as an ipsilateral-to-contralateral OEF ratio greater than 1.13 (73). Furthermore, OEF may be measured by certain MRI sequences (74-77). In addition to MRI, the mean transit time of CT perfusion is an optimum correlate of PET-measured OEF, and thus also provides an effective measure of OEF $(73,78)$. 


\section{Indications for surgical treatment}

The selection criteria for treatment of CTO of the ICA are controversial (79). It is debated whether revascularization should be performed in asymptomatic patients with CTO of the ICA and stage I hemodynamic failure (42). However, for symptomatic patients with stage I or II hemodynamic failure, revascularization is recommended (80). The COSS test criteria should also be addressed, as it further applies to treatment indications for CTO of the ICA (8).

Corresponding clinical symptoms. The primary clinical symptoms include transient ischemic attack or ischemic stroke with mild to moderate permanent ischemic neurological deficit in the hemispheric carotid territory ipsilateral to the occluded carotid artery, occurring within 120 days (8). To receive optimal benefit from revascularization, patients should be in satisfactory clinical condition, though also symptomatic with clinical and radiographic confirmation of a recent non-embolic ischemic event (81).

Increased OEF ratio. OEF as measured by PET is a gold standard to evaluate cerebral blood flow. Testing conducted as part of the COSS established it as an important surgery standard applicable to recanalization treatment of CTO of the ICA; when the ipsilateral-to-contralateral OEF ratio is greater than 1.13 , the indication for surgical treatment is considered to be clear (8). Patients with stage II hemodynamic failure comprise the majority of these cases as stage II hemodynamic failure causes collapse of the vascular reserve in combination with an increase in OEF (82). OEF as measured by PET is an effective predictor of subsequent stroke for symptomatic patients (15).

Reverse filling of vessels. Retrograde filling is an important criterion for recanalization treatment of CTO of the ICA. The accumulated blood should at least fill the ophthalmic artery and, optimally, should reach the petrous level of the ICA (38). These angiographic features indicate the presence of a focal occlusion in the extracranial compartment of the ICA (83). However, guide wire manipulation is particularly difficult in this situation; therefore, visualization of the distal ICA by ipsilateral contrast injection may provide a clear reference for the wiring procedure (38).

\section{Treatments}

Treatment options for CTO of the ICA include best medical treatment, CEA, percutaneous stenting, a combination of these measures, and, previously, surgical external carotid-internal carotid (EC-IC) bypass (84).

Conservative treatments. Best medical treatment is indicated for CTO of the ICA with stable hemodynamics and full compensation $(46,85)$. In addition, conservative treatments are adopted for patients who decline surgical retreatment. For patients receiving conservative treatments, oral antiplatelet aggregation drugs including as aspirin are required. Combination therapy with clopidogrel and aspirin is more effective than aspirin alone in reducing asymptomatic embolization (86). However, best medical treatment is unable to comprehensively treat CTO of the ICA, and only minimizes the risk of stroke (84).

CEA. It is feasible to treat CTO of the ICA with CEA therapy, as an established method in the treatment of ICA occlusion (87). CEA may be performed in patients with retrograde filling to the skull base (88). However, CEA may also fail in severe cases exhibiting complex clot organization, and if the thrombotic process exhibits intracranial extension; thus restoring circulation following complete occlusion is a challenging procedure. Thompson et al reported that recanalization was achieved in only $41 \%$ of 118 patients undergoing CEA for chronic ICA occlusion after a 13-year follow-up (89).

Endovascular therapy. In contrast to CEA, endovascular access is flexible and not limited to the extracranial space. A variety of tools are available to complete the intracranial revascularization process, though stenting is considered the most effective method for breaking down complex clots $(40,90)$. In terms of surgical technique, initial penetration of the occluded stump from the anterior side may provide a maximal chance to access the 'true lumen'. This may be related to the posterior-to-anterior progression of the plaque at the common carotid artery bifurcation (91).

Endovascular treatment may resolve CTO of the ICA. In 2008, Lin et al (49) reported the results of endovascular revascularization in a series of 54 patients; recanalization was achieved in 65\% (35 patients). In 2016, Chen et al (38) reviewed attempted endovascular procedures in 138 consecutive patients with CTO of the ICA, and identified a technical success rate of $61.6 \%$.

A prominent drawback of intravascular interventional therapy is that the thrombus may dislodge and enter the circulation during the balloon dilation or the release of the stent, and consequently block an intracranial artery (92). For this reason, some clinicians have attempted to use protection devices, in some cases to protect the common carotid artery, the external carotid artery and the ICA concurrently $(93,94)$. For instance, the Parodi embolic protection system has been used $(95,96)$. However, there may be limited application; for example, if the thrombus occupies an occluded vessel with retrograde flow, proximal occlusion would not necessarily provide additional protection (97). In addition to carotid artery stents, telescoped flow diverters may also be adopted to treat symptomatic CTO of the ICA (98).

Hybrid surgery. In recent years, the increased feasibility of hybrid surgery has made it possible to combine CEA of the proximal ICA with endovascular angioplasty of the distal ICA in a hybrid operation procedure (99). Hybrid surgery is considered to be a feasible and favorable alternative surgical procedure; a higher success rate may be achieved using the hybrid technique as it can provide improved control of endovascular manipulation (100). In 2013, Shih et al (39) successfully used this method to treat 3 cases with recurrent ischemic attacks due to CTO of the ICA.

Hybrid surgery refers to a process in which CEA is first performed in the initial part of the ICA, following which a guiding catheter is placed into the surgical field via the common carotid artery; subsequently, a micro-guidewire 
and micro-guide catheter are placed in the distal end of the ICA in direct view and maneuvered to the cavernous sinus or the ophthalmic artery under radioscopy (101). Under microcatheter radiography, if the distal vessels are developed, the carotid artery is sutured and the CEA is completed, and the stent is laid down along the micro-guidewire until the artery is recanalized (102). Hybrid surgery is relatively safe as the CEA is open and debris may filtrate from the surgical field, aiding to prevent distal embolic accidents (100).

EC-IC bypass. CTO of the ICA may be managed by EC-IC bypass, as tested in the COSS $(8,103)$. However, EC-IC bypass surgeries typically connect the superficial temporal artery to the middle cerebral artery; this is a low-flow bypass, and the shunted blood flow may not be adequate (104). Additionally, compared with medical therapy alone, EC-IC bypass surgery plus medical therapy did not reduce the risk of recurrent ipsilateral ischemic stroke at 2 years (8).

The failure of EC-IC bypass in the COSS was probably caused by failure to select patients at high risk of stroke. Whether EC-IC bypass has applications in the treatment of advanced occlusive vascular disease patients requires verification (105).

Overall, future research should address the remaining challenges of developing and investigating novel surgical treatments for the disease process, and establish the clinical benefit of such treatments through randomized controlled trials (106).

\section{Factors affecting recanalization}

Numerous factors may affect the success rate of recanalization, including the duration, extent and causes of carotid artery occlusion; the presence of carotid artery calcification and plaque formation; the degree of reverse filling in the vessels; and the choice of treatment (93).

Duration of occlusion. The factor that most prominently affects the success rate of recanalization is the duration of occlusion. For acute and subacute occlusion of the ICA, both interventional surgery and hybrid surgery are relatively straightforward, mainly as the thrombosis in the ICA has not developed in structure and is relatively soft $(91,107)$. Our experience corroborates this finding. For CTO of the ICA, the thrombosis at the distal end of the ICA may occasionally be directly pulled out following CEA, and the vessels may be recanalized (108). Under the restored blood flow and blood pressure, the atrophied and collapsed vessels distal to the thrombus are restored to normal diameter and morphology during follow-up (109). As the duration of ICA occlusion increases, the clot undergoes complete fibrotic organization at the ICA origin, hindering the passage of the micro-guidewire through the occluded arteries; the difficulty of recanalization is thereby increased, as is the risk of complications (110).

Length and height of the occlusion. The longer the duration of a CTO of the ICA, the lower the predicted technical success of recanalization (111). A microwire must pass thorough the occluded arteries during recanalization, and this process is difficult due to the variable course of the vessel, which frequently results in false lumen creation (112). In 2016,
Chen et al (38) categorized occlusion length using a cut-off of $5 \mathrm{~cm}$, and identified that the technical success rates for occlusions shorter than $5 \mathrm{~cm}$ and longer than $5 \mathrm{~cm}$ were 73.7 and $59.7 \%$, respectively, suggesting a higher success rate of recanalization for occlusions shorter than $5 \mathrm{~cm}$. They also observed that the success rates of distal ICA reconstitution at the petrous segment or below; at the cavernous, clinoid and ophthalmic segments; and at the communicating segment or above were 93, 80, 73, 33 and 29\%, respectively. This indicated that the lower the location of the ICA occlusion, the higher the success rate of recanalization (38).

Atherosclerosis in the initial part of the ICA. If the CTO of the ICA is derived from atherosclerosis associated with calcification in the initial segment of the ICA, then severe atherosclerosis and calcification in the occluded segment may hinder the placement of the guidewire (113). Our experience is that for CTO of the ICA with recanalization, CTA or ultrasound inspection is often performed to judge whether severe atherosclerosis is present in the occlusion of the initial segment of the carotid artery. If there is arterial sclerosis or calcification, CEA is typically performed in a hybrid operating room first, followed by endovascular recanalization in the distal end of the carotid artery.

Other factors. Recanalization of CTO of the ICA is not dependent on any one factor. Chen et al (38) reported in 2016 on 138 consecutive patients undergoing endovascular treatments for CTO of the ICA, and evaluated the following four factors: Neurological events, stump morphology, distal carotid artery reconstitution and level of distal carotid artery reconstitution. They identified that the absence of prior neurological events, a non-tapered stump, distal ICA reconstitution via contralateral injection and distal ICA reconstitution at the communicating or ophthalmic segment were independent negative predictors for technical success in endovascular recanalization for CTO of the ICA. These factors also affect the success rate of hybrid surgery (39). In addition, it is possible that the success of the procedure is associated with previous anticoagulant therapy, which maintains a soft consistency of the thrombus, facilitating advancement through the occlusion (114).

\section{Complications of treatment}

It remains difficult to treat CTO of the ICA, and the condition is associated with high mortality rate and risk of stroke. The main factors summarized below include complications following recanalization and technology-related complications (50).

Complications following recanalization. In certain cases, long-term carotid artery occlusion has impaired the CVR of the ipsilateral hemisphere, leaving the patient prone to excessive perfusion following recanalization; the characteristics of excessive perfusion include headache, bleeding disorders, epilepsy and in some cases, parenchymal and subarachnoid hemorrhage. Chen et al (38) used endovascular treatment on the 138 consecutive cases of CTO of the ICA, and hyperperfusion syndrome with delayed nonfatal intracranial hemorrhage developed in 2 patients. To mitigate this risk, the 
physician should retain the patient's systolic blood pressure low $(<120 \mathrm{mmHg})$ in the periprocedural period (115).

Technology-related complications. These complications primarily arise from the carotid artery with recanalization, whereby detachment of the thrombus may result in symptomatic and asymptomatic embolic events (37). There is a high risk of distal migration of the thrombus upon catheterization through the thrombus and stenting; consequently, a protective device is sometimes required (116). In addition, the micro-guidewire may inflict injuries, including vessel perforation of the carotid artery, pseudoaneurysm, arterial dissection or carotid-cavernous fistula (93).

\section{Prognosis}

Recanalization treatment is considered a viable treatment option for CTO of the ICA. In 2010, Terada et al (95) treated 15 cases, of which 14 exhibited successful recanalization on angiographic follow-up between 6 and 12 months after the procedure, suggesting that endovascular recanalization of the chronically occluded ICA is feasible and achieves acceptable midterm follow-up results during the follow-up period. Iwata et al (5) also suggested in 2012 that chronic carotid occlusions of over 3 months old and limited to the cervical area may be opened safely, with favorable angiographic and long-term clinical outcomes. A major problem that affects the prognosis of CTO of ICA is the presence of reocclusion following recanalization. It is considered that maintenance of the recanalization mainly depends on the occlusion site; in a previous study, the rates of reocclusion within 1 year were $91 \%$ in those with occlusions distal to the clinoid segment and $0 \%$ in those with occlusions proximal to the clinoid segment (12).

If CTO of the ICA can be recanalized without complications, this is the ideal treatment. However, the success rate for recanalizing occlusions is as low as $34 \%$ due to the technical difficulty of the procedure; therefore, the prospects of the technique remain relatively unfavorable (38). Hybrid surgery may improve the success rate of surgery as removing the plaque at the initial segment of the carotid artery reduces the complexity of recanalization surgery. Nonetheless, the surgical indications should be followed strictly. Recanalization of CTO of the ICA can effectively reduce the incidence of cerebral infarction, and successful recanalization may effectively improve global cognitive function, attention and psychomotor processing speed compared with medical treatment $(117,118)$.

\section{Conclusion}

For cases of CTO of the ICA, in the presence of clear indicators, recanalization should be performed as the main strategy, since EC-IC bypass has been demonstrated to be ineffective. Endovascular interventional recanalization, CEA and hybrid surgery may also be conducted in a select group of patients. With the development of novel materials, the success rate of simple recanalization may gradually increase. Hybrid surgery may be more representative of the current trend in treatment, as advanced CEA can remove carotid atherosclerosis plaques, thus reducing the difficulty of the subsequent interventional recanalization technique. Successful and stable recanaliza- tion should improve clinical outcome for patients by reducing ischemic symptoms and preventing the recurrence of ischemic symptoms in the long-term.

\section{References}

1. Otite FO, Khandelwal P, Malik AM and Chaturvedi S: National Patterns of Carotid Revascularization Before and After the Carotid Revascularization Endarterectomy vs Stenting Trial (CREST). JAMA Neurol: Dec 4, 2017 (Epub ahead of print).

2. Lichtman JH, Jones MR, Leifheit EC, Sheffet AJ, Howard G, Lal BK, Howard VJ, Wang Y, Curtis J and Brott TG: Carotid Endarterectomy and Carotid Artery Stenting in the US Medicare Population, 1999-2014. JAMA 318: 1035-1046, 2017.

3. Ma Y, Gu Y, Tong X, Wang J, Kuai D, Wang D, Ren J, Duan L, Maimaiti A, Cai Y, et al: The Carotid and Middle cerebral artery Occlusion Surgery Study (CMOSS): A study protocol for a randomised controlled trial. Trials 17: 544, 2016.

4. Michel P, Ntaios G, Delgado MG, Bezerra DC, Meuli R and Binaghi S: CT angiography helps to differentiate acute from chronic carotid occlusion: The 'carotid ring sign'. Neuroradiology 54: 139-146, 2012.

5. Iwata T,Mori T, Tajiri H, Miyazaki Y and Nakazaki M: Long-term angiographic and clinical outcome following stenting by flow reversal technique for chronic occlusions older than 3 months of the cervical carotid or vertebral artery. Neurosurgery 70: 82-90, discussion 90, 2012.

6. Usachev DY, Lukshin VA, Shmigel'skiy AV and Akhmedov AD: An anastomosis between the internal carotid and vertebral arteries in the treatment of a patient with bilateral carotid arteries occlusions. Vopr Neirokhir 80: 72-77, 2016.

7. Esposito G, Amin-Hanjani S and Regli L: Role of and Indications for Bypass Surgery After Carotid Occlusion Surgery Study (COSS)? Stroke 47: 282-290, 2016.

8. Powers WJ, Clarke WR, Grubb RL Jr, Videen TO, Adams HP Jr and Derdeyn CP; COSS Investigators: Extracranial-intracranial bypass surgery for stroke prevention in hemodynamic cerebral ischemia: the Carotid Occlusion Surgery Study randomized trial. JAMA 306: 1983-1992, 2011.

9. Grubb RL Jr, Powers WJ, Clarke WR, Videen TO, Adams HP Jr and Derdeyn CP; Carotid Occlusion Surgery Study Investigators: Surgical results of the Carotid Occlusion Surgery Study. J Neurosurg 118: 25-33, 2013.

10. Rocha M, Delfyett WT, Agarwal V, Aghaebrahim A, Jadhav A and Jovin TG: Diagnostic accuracy of emergency CT angiography for presumed tandem internal carotid artery occlusion before acute endovascular therapy. J Neurointerv Surg neurintsurg-2017-013169, 2017.

11. Diouf A, Fahed R, Gaha M, Chagnon M, Khoury N, Kotowski M, Guilbert F, Landry D, Raymond J, Roy D, et al: Cervical Internal Carotid Occlusion versus Pseudo-occlusion at CT Angiography in the Context of Acute Stroke: An Accuracy, Interobserver, and Intraobserver Agreement Study. Radiology: Oct 25, 2017 (Epub ahead of print).

12. Lee CW, Lin YH, Liu HM, Wang YF, Chen YF and Wang JL: Predicting procedure successful rate and 1-year patency after endovascular recanalization for chronic carotid artery occlusion by CT angiography. Int J Cardiol 221: 772-776, 2016.

13. Powers WJ, Derdeyn CP, Fritsch SM, Carpenter DA, Yundt KD, Videen TO and Grubb RL Jr: Benign prognosis of never-symptomatic carotid occlusion. Neurology 54: 878-882, 2000.

14. Cheema S, Clarke-Moloney M, Kavanagh EG, Burke PE and Grace PA: Natural history and clinical outcome of patients with documented carotid artery occlusion. Ir J Med Sci 176: 289-291, 2007.

15. Grubb RL Jr, Derdeyn CP, Fritsch SM, Carpenter DA, Yundt KD, Videen TO, Spitznagel EL and Powers WJ: Importance of hemodynamic factors in the prognosis of symptomatic carotid occlusion. JAMA 280: 1055-1060, 1998.

16. Cote R, Barnett HJ and Taylor DW: Internal carotid occlusion: A prospective study. Stroke 14: 898-902, 1983.

17. Delgado MG, Vega PP, Lahoz CH and Calleja S: Late spontaneous recanalization of symptomatic atheromatous internal carotid artery occlusion. Vascular 23: 211-216, 2015.

18. Morris-Stiff G, Teli M, Khan PY, Ogunbiyi SO, Champ CS, Hibberd R, Brown R, Bailey DM, Winter RK and Lewis MH: Internal carotid artery occlusion: Its natural history including recanalization and subsequent neurological events. Vasc Endovascular Surg 47: 603-607, 2013. 
19. Camporese G, Labropoulos N, Verlato F, Bernardi E, Ragazzi R, Salmistraro G, Kontothanassis D and Andreozzi GM; Carotid Recanalization Investigators Group: Benign outcome of objectively proven spontaneous recanalization of internal carotid artery occlusion. J Vasc Surg 53: 323-329, 2011.

20. Shchanitsyn IN, Maksyushina TD, Titova YI, Persova EA, Bazhanov SP and Karavaikin PA: Spontaneous recanalization of chronic occlusion of the internal carotid artery. Angiol Sosud Khir 21: 124-135, 2015

21. Buslovich S and Hines GL: Spontaneous recanalization of chronic internal carotid artery occlusions: Report of 3 cases. Vasc Endovascular Surg 45: 93-97, 2011.

22. Yang C, Bogiatzi C and Spence JD: Risk of Stroke at the Time of Carotid Occlusion. JAMA Neurol 72: 1261-1267, 2015.

23. Matic P,Ilijevski N, Radak S, Kolar J and Radak D: Recanalization of chronic carotid occlusion: Case report and review of the literature. Vascular 17: 281-283, 2009.

24. Surikova I, Meisel S, Siebler M, Wittsack HJ and Seitz RJ: Significance of the perfusion-diffusion mismatch in chronic cerebral ischemia. J Magn Reson Imaging 24: 771-778, 2006

25. Liebeskind DS: Collateral circulation. Stroke 34: 2279-2284, 2003.

26. Liebeskind DS, Cotsonis GA, Saver JL, Lynn MJ, Turan TN, Cloft HJ and Chimowitz MI; Warfarin-Aspirin Symptomatic Intracranial Disease (WASID) Investigators: Collaterals dramatically alter stroke risk in intracranial atherosclerosis. Ann Neurol 69: 963-974, 2011

27. Pipinos II, Pisimisis GT, Burjonrappa SC, Johanning JM Longo GM and Lynch TG: One patent intracranial collateral predicts tolerance of flow reversal during carotid angioplasty and stenting. Ann Vasc Surg 23: 32-38, 2009.

28. Sundaram S, Kannoth S, Thomas B, Sarma PS and Sylaja PN: Collateral Assessment by CT Angiography as a Predictor of Outcome in Symptomatic Cervical Internal Carotid Artery Occlusion. AJNR Am J Neuroradiol 38: 52-57, 2017.

29. Choi HJ, Sohn CH, You SH, Yoo RE, Kang KM, Yun TJ, Choi SH, Kim JH, Cho WS and Kim JE: Can Arterial Spin-Labeling with Multiple Postlabeling Delays Predict Cerebrovascular Reserve? AJNR Am J Neuroradiol: Nov 16, 2017 (Epub ahead of print).

30. Gupta A, Chazen JL, Hartman M, Delgado D, Anumula N, Shao H, Mazumdar M, Segal AZ, Kamel H, Leifer D, et al: Cerebrovascular reserve and stroke risk in patients with carotid stenosis or occlusion: A systematic review and meta-analysis. Stroke 43: 2884-2891, 2012.

31. Quilitz B, Rimpel J, Mehdorn M, Rohm N and Lehmann HJ Cerebrovascular reserve capacity (CRC) in carotid artery disease: A routine test in selection for surgical treatment? Thorac Cardiovasc Surg 36: 217-220, 1988.

32. Seiler A, Deichmann R, Pfeilschifter W, Hattingen E, Singer OC and Wagner M: T2-Imaging to Assess Cerebral Oxygen Extraction Fraction in Carotid Occlusive Disease: Influence of Cerebral Autoregulation and Cerebral Blood Volume. PLoS One 11: e0161408, 2016.

33. Powers WJ, Press GA, Grubb RL Jr, Gado M and Raichle ME: The effect of hemodynamically significant carotid artery disease on the hemodynamic status of the cerebral circulation. Ann Intern Med 106: 27-34, 1987.

34. Derdeyn CP, Grubb RL Jr and Powers WJ: Cerebral hemodynamic impairment: Methods of measurement and association with stroke risk. Neurology 53: 251-259, 1999.

35. Harrison MJ and Marshall J: The finding of thrombus at carotic endarterectomy and its relationship to the timing of surgery. Br J Surg 64: 511-512, 1977

36. Chen YH and Kao HL: Concern on article 'Predicting procedure successful rate and 1-year patency after endovascular recanalization for chronic carotid artery occlusion by CT angiography'. Int J Cardiol 229: 59, 2017

37. Nico L, Cester G, Viaro F, Baracchini C and Causin F: Endovascular recanalization of the common carotid artery in a patient with radio induced chronic occlusion. J Neurointerv Surg 9: e23, 2017.

38. Chen YH, Leong WS, Lin MS, Huang CC, Hung CS, Li HY, Chan KK, Yeh CF, Chiu MJ and Kao HL: Predictors for Successful Endovascular Intervention in Chronic Carotid Artery Total Occlusion. JACC Cardiovasc Interv 9: 1825-1832, 2016.

39. Shih YT, Chen WH, Lee WL, Lee HT, Shen CC and Tsuei YS: Hybrid surgery for symptomatic chronic total occlusion of carotid artery: a technical note. Neurosurgery 73: onsE117-123; discussion onsE123, 2013.
40. Komiyama M, Yoshimura M, Honnda Y, Matsusaka Y and Yasui T: Percutaneous angioplasty of a chronic total occlusion of the intracranial internal carotid artery. Case report. Surg Neurol 66: 513-518, discussion 518, 2006.

41. Heck D: Endovascular Intervention in Chronic Total Carotid Artery Occlusion: It Can be Done, But When Should it be Done? JACC Cardiovasc Interv 9: 1833-1834, 2016.

42. Hauck EF, Ogilvy CS, Siddiqui AH, Hopkins LN and Levy EI Direct endovascular recanalization of chronic carotid occlusion: should we do it? Case report. Neurosurgery 67: E1152-1159; discussion E1159, 2010.

43. Derdeyn CP, Grubb RL Jr and Powers WJ: Indications for cerebral revascularization for patients with atherosclerotic carotid occlusion. Skull Base 15: 7-14, 2005.

44. Casey K, Hitchner E, Lane B and Zhou W: Contralateral microemboli following carotid artery stenting in patients with a contralateral internal carotid artery occlusion. J Vasc Surg 58: 794-797, 2013.

45. Jokinen H, Schmidt R, Ropele S, Fazekas F, Gouw AA, Barkhof F, Scheltens P, Madureira S, Verdelho A, Ferro JM, et al; LADIS Study Group: Diffusion changes predict cognitive and functional outcome: The LADIS study. Ann Neurol 73: 576-583, 2013.

46. Damania D, Kung NT, Jain M, Jain AR, Liew JA, Mangla R, Koch GE, Sahin B, Miranpuri AS, Holmquist TM, et al: Factors associated with recurrent stroke and recanalization in patients presenting with isolated symptomatic carotid occlusion. Eur J Neurol 23: 127-132, 2016.

47. Rutgers DR, van Osch MJ, Kappelle LJ, Mali WP and van der Grond J: Cerebral hemodynamics and metabolism in patients with symptomatic occlusion of the internal carotid artery. Stroke 34: 648-652, 2003.

48. Sam K, Small E, Poublanc J, Han JS, Mandell DM, Fisher JA, Crawley AP and Mikulis DJ: Reduced contralateral cerebrovascular reserve in patients with unilateral steno-occlusive disease. Cerebrovasc Dis 38: 94-100, 2014.

49. Lin MS, Lin LC, Li HY, Lin CH, Chao CC, Hsu CN, Lin YH, Chen SC, Wu YW and Kao HL: Procedural safety and potential vascular complication of endovascular recanalization for chronic cervical internal carotid artery occlusion. Circ Cardiovasc Interv 1: 119-125, 2008

50. Kao HL, Lin MS, Wang CS, Lin YH, Lin LC, Chao CL, Jeng JS, Yip PK and Chen SC: Feasibility of endovascular recanalization for symptomatic cervical internal carotid artery occlusion. J Am Coll Cardiol 49: 765-771, 2007.

51. Fan YL, Wan JQ, Zhou ZW, Chen L, Wang Y, Yao Q and Jiang JY: Neurocognitive improvement after carotid artery stenting in patients with chronic internal carotid artery occlusion: A prospective, controlled, single-center study. Vasc Endovascular Surg 48: 305-310, 2014.

52. Hage ZA, Behbahani M, Amin-Hanjani S and Charbel FT: Carotid bypass for carotid occlusion. Curr Atheroscler Rep 17: $36,2015$.

53. Toyama H, Takeshita G, Takeuchi A, Anno H, Ejiri K, Maeda H, Katada K, Koga S, Ishiyama N, Kanno T, et al: Cerebral hemodynamics in patients with chronic obstructive carotid disease by rCBF, rCBV, and rCBV/rCBF ratio using SPECT. J Nucl Med 31: 55-60, 1990 .

54. Ida K, Akaki S, Sei T, Tsunoda M and Kanazawa S: Cerebral perfusion MR imaging using FAIR-HASTE in chronic carotid occlusive disease: Comparison with dynamic susceptibility contrast-perfusion MR imaging. Acta Med Okayama 60: 215-221, 2006.

55. Lassalle L, Turc G, Tisserand M, Charron S, Roca P, Lion S, Legrand L, Edjlali M, Naggara O, Meder JF, et al: ASPECTS (Alberta Stroke Program Early CT Score) Assessment of the Perfusion-Diffusion Mismatch. Stroke 47: 2553-2558, 2016.

56. Miyazawa N, Arbab AS, Umeda T and Akiyama I: Perfusion CT investigation of chronic internal carotid artery occlusion: Comparison with SPECT. Clin Neurol Neurosurg 108: 11-17, 2005.

57. Mukherjee P, Kang HC, Videen TO, McKinstry RC, Powers WJ and Derdeyn CP: Measurement of cerebral blood flow in chronic carotid occlusive disease: Comparison of dynamic susceptibility contrast perfusion MR imaging with positron emission tomography. AJNR Am J Neuroradiol 24: 862-871, 2003.

58. Mylonas SN, Antonopoulos CN, Moulakakis KG, Kakisis JD and Liapis CD: Management of Patients with Internal Carotid Artery Near-total Occlusion: An Updated Meta-analysis. Ann Vasc Surg 29: 1664-1672, 2015 
59. Lee JI, Jander S, Oberhuber A, Schelzig H, Hänggi D, Turowski B and Seitz RJ: Stroke in patients with occlusion of the internal carotid artery: Options for treatment. Expert Rev Neurother 14: 1153-1167, 2014.

60. Yoshida K, Fukumitsu R, Kurosaki Y, Funaki T, Kikuchi T, Takahashi JC, Takagi Y, Yamagata S and Miyamoto S: The association between expansive arterial remodeling detected by high-resolution MRI in carotid artery stenosis and clinical presentation. J Neurosurg 123: 434-440, 2015.

61. Bae YJ,Jung C, Kim JH, Choi BS and KimE: Quantitative Magnetic Resonance Angiography in Internal Carotid Artery Occlusion with Primary Collateral Pathway. J Stroke 17: 320-326, 2015.

62. Kuroda S, Houkin K, Kamiyama H, Mitsumori K, Iwasaki Y, Abe H, Yonas H, Wechsler LR, Nemoto E and Pindzola R: Long-term prognosis of medically treated patients with internal carotid or middle cerebral artery occlusion: Can acetazolamide test predict it? Stroke 32: 2110-2116, 2001.

63. Vernieri F, Pasqualetti P, Passarelli F, Rossini PM and Silvestrini M: Outcome of carotid artery occlusion is predicted by cerebrovascular reactivity. Stroke 30: 593-598, 1999

64. Douvas I, Moris D, Karaolanis G, Bakoyiannis C and Georgopoulos S: Evaluation of cerebrovascular reserve capacity in symptomatic and asymptomatic internal carotid stenosis with transcranial Doppler. Physiol Res 65: 917-925, 2016.

65. Yang F, Shi W, Shi J, Zhang Y, Yin Y, Shi H and Chen D: Assessment of cerebrovascular reserve in unilateral middle cerebral artery stenosis using perfusion $\mathrm{CT}$ and $\mathrm{CO} 2$ inhalation tests. Int J Neurosci 127: 320-325, 2017.

66. Okudaira Y, Nakanishi H, Arai H and Sato K: Differences in acetazolamide vasoreactivity in patients with acute and chronic occlusion of the internal carotid artery. J Clin Neurosci 10: 316-319, 2003.

67. Wu J, Dehkharghani S, Nahab F and Qiu D Acetazolamide-augmented dynamic BOLD (aczBOLD) imaging for assessing cerebrovascular reactivity in chronic steno-occlusive disease of the anterior circulation: An initial experience. Neuroimage Clin 13: 116-122, 2016.

68. Kawai N, Kawanishi M, Shindou A, Kudomi N, Yamamoto Y, Nishiyama Y and Tamiya T: Cerebral blood flow and metabolism measurement using positron emission tomography before and during internal carotid artery test occlusions: Feasibility of rapid quantitative measurement of $\mathrm{CBF}$ and $\mathrm{OEF} / \mathrm{CMRO}(2)$. Interv Neuroradiol 18: 264-274, 2012.

69. Yonas H, Smith HA, Durham SR, Pentheny SL and Johnson DW: Increased stroke risk predicted by compromised cerebral blood flow reactivity. J Neurosurg 79: 483-489, 1993.

70. Suzuki T, Ogasawara K, Kuroda H, Chida K, Aso K, Kobayashi M Fujiwara S, Yoshida K, Terasaki K and Ogawa A: Comparison of early and late images on 123I-iomazenil SPECT with cerebral blood flow and oxygen extraction fraction images on PET in the cerebral cortex of patients with chronic unilateral major cerebral artery occlusive disease. Nucl Med Commun 33: 171-178, 2012.

71. Nariai T, Ohno K, Akimoto H, Ohta Y, Nagaoka T, Hirakawa K, Ishii $\mathrm{K}$ and Senda M: Cerebral blood flow, vascular response and metabolism in patients with MELAS syndrome - xenon CT and PET study. Keio J Med 49 (Suppl 1): A68-A70, 2000.

72. Eicker SO, Turowski B, Heiroth HJ, Steiger HJ and Hänggi D: A comparative study of perfusion CT and $99 \mathrm{~m}$ Tc-HMPAO SPECT measurement to assess cerebrovascular reserve capacity in patients with internal carotid artery occlusion. Eur J Med Res 16: 484-490, 2011.

73. Kamath A, Smith WS, Powers WJ, Cianfoni A, Chien JD, Videen T, Lawton MT, Finley B, Dillon WP and Wintermark M: Perfusion CT compared to $\mathrm{H}(2)$ (15)O/O (15)O PET in patients with chronic cervical carotid artery occlusion. Neuroradiology 50 745-751, 2008

74. Kämpe R, Lind E, Ståhlberg F, van Westen D, Knutsson L and Wirestam R: Quantification of normal cerebral oxygen extraction and oxygen metabolism by phase-based MRI susceptometry: Evaluation of repeatability using two different imaging protocols. Clin Physiol Funct Imaging 37: 211-220, 2017.

75. De Vis JB, Petersen ET, Alderliesten T, Groenendaal F, de Vries LS, van Bel F, Benders MJ and Hendrikse J: Non-invasive MRI measurements of venous oxygenation, oxygen extraction fraction and oxygen consumption in neonates. Neuroimage 95: 185-192, 2014

76. Jordan LC, Gindville MC, Scott AO, Juttukonda MR, Strother MK, Kassim AA, Chen SC, Lu H, Pruthi S, Shyr Y, et al: Non-invasive imaging of oxygen extraction fraction in adults with sickle cell anaemia. Brain 139: 738-750, 2016
77. Merola A, Murphy K, Stone AJ, Germuska MA, Griffeth VEM, Blockley NP, Buxton RB and Wise RG: Measurement of oxygen extraction fraction (OEF): An optimized BOLD signal model for use with hypercapnic and hyperoxic calibration. Neuroimage 129: 159-174, 2016.

78. Yamauchi H, Fukuyama H, Nagahama Y, Katsumi Y and Okazawa H: Cerebral hematocrit decreases with hemodynamic compromise in carotid artery occlusion: A PET study. Stroke 29: 98-103, 1998

79. Powers WJ: Cerebral hemodynamics in ischemic cerebrovascular disease. Ann Neurol 29: 231-240, 1991.

80. Kuroda S, Kawabori M, Hirata K, Shiga T, Kashiwazaki D, Houkin K and Tamaki N: Clinical significance of STA-MCA double anastomosis for hemodynamic compromise in post-JET/COSS era. Acta Neurochir (Wien) 156: 77-83, 2014

81. Carlson A, Yonas H and Nemoto EM: Response to Letter by Powers Regarding Article, 'Failure of Cerebral Hemodynamic Selection in General or of Specific Positron Emission Tomography Methodology? Carotid Occlusion Surgery Study (COSS). Stroke 43: e44, 2012

82. Kashiwazaki D, Kuroda S, Terasaka S and Iwasaki Y: Detection of hemodynamic transient ischemic attack during hemodialysis with near-infrared monitoring in a patient with internal carotid artery occlusion. Surg Neurol 68: 292-294, discussion 294-295, 2007.

83. Yu LB, He H, Zhao JZ, Wang R, Zhang Q, Shi ZY, Shao JS and Zhang D: More Precise Imaging Analysis and Diagnosis of Moyamoya Disease and Moyamoya Syndrome Using High-Resolution Magnetic Resonance Imaging. World Neurosurg 96: 252-260, 2016.

84. Radak DJ, Tanaskovic S, Ilijevski NS, Davidovic L, Kolar J, Radak S and Otasevic P: Eversion carotid endarterectomy versus best medical treatment in symptomatic patients with near total internal carotid occlusion: A prospective nonrandomized trial Ann Vasc Surg 24: 185-189, 2010.

85. Gomensoro JB: Joint study of extracranial arterial occlusion. 8 . Clinical-radiographic correlation of carotid bifurcation lesions in 177 patients with transient cerebral ischemic attacks. JAMA 224: 985-991, 1973

86. Markus HS, Droste DW, Kaps M, Larrue V, Lees KR, Siebler M and Ringelstein EB: Dual antiplatelet therapy with clopidogrel and aspirin in symptomatic carotid stenosis evaluated using doppler embolic signal detection: The Clopidogrel and Aspirin for Reduction of Emboli in Symptomatic Carotid Stenosis (CARESS) trial. Circulation 111: 2233-2240, 2005.

87. Blaisdell FW, Hall AD and Thomas AN: Surgical treatment of chronic internal carotid artery occlusion by saline endarterectomy. Ann Surg 163: 103-111, 1966.

88. Greiner C, Wassmann H, Palkovic S and Gauss C: Revascularization procedures in internal carotid artery pseudo-occlusion. Acta Neurochir (Wien) 146: 237-243, discussion 243, 2004.

89. Thompson JE, Austin DJ and Patman RD: Carotid endarterectomy for cerebrovascular insufficiency: Long-term results in 592 patients followed up to thirteen years. Surg Clin North Am 66: 233-253, 1986.

90. Kim WH, Min PK, Kim DJ and Shim WH: Successful carotid stenting for chronic total occlusion of the internal carotid artery. Korean Circ J 40: 288-291, 2010.

91. Namba K, Shojima M and Nemoto S: Wire-probing technique to revascularize subacute or chronic internal carotid artery occlusion. Interv Neuroradiol 18: 288-296, 2012.

92. Dalyai RT, Chalouhi N, Singhal S, Jabbour P, Gonzalez LF, Dumont AS, Rosenwasser R, Ghobrial G and Tjoumakaris SI: Stent-assisted endovascular recanalization of extracranial internal carotid artery occlusion in acute ischemic stroke. World Neurosurg 79: 143-148, 2013.

93. Terada T, Yamaga H, Tsumoto T, Masuo O and Itakura T: Use of an embolic protection system during endovascular recanalization of a totally occluded cervical internal carotid artery at the chronic stage. Case report. J Neurosurg 102: 558-564, 2005.

94. Shojima M, Nemoto S, Morita A, Miyata T, Namba K, Tanaka Y and Watanabe E: Protected endovascular revascularization of subacute and chronic total occlusion of the internal carotid artery. AJNR Am J Neuroradiol 31: 481-486, 2010.

95. Terada T, Okada H, Nanto M, Shintani A, Yoshimura R, Kakishita K, Masuo O, Matsumoto H, Itakura T, Ohshima K, et al: Endovascular recanalization of the completely occluded internal carotid artery using a flow reversal system at the subacute to chronic stage. J Neurosurg 112: 563-571, 2010. 
96. Ishihara H, Sakai N, Kuroiwa T, Sakaguchi M, Morizane A, Sakai C, Yano T, Kajikawa R, Yamagami H and Kobayashi J: Percutaneous transluminal angioplasty and stenting for chronic total occlusion of intracranial carotid artery: A case report. Interv Neuroradiol 12: 263-268, 2006.

97. Bhatt A, Majid A, Kassab M and Gupta R: Chronic total symptomatic carotid artery occlusion treated successfully with stenting and angioplasty. J Neuroimaging 19: 68-71, 2009.

98. Cohen JE, Gomori JM, Ben-Hur T, Moscovici S and Itshayek E: The use of telescoped flow diverters as an endovascular bypass in the management of symptomatic chronic carotid occlusion. J Clin Neurosci 19: 1026-1028, 2012.

99. Marino M, Kasemi H, Di Angelo CL and Fadda GF: Hybrid treatment of symptomatic chronic isolated carotid bifurcation. Ann Vasc Surg 28: 1795.e7-1795.e10, 2014.

100.Pintér L, Cagiannos C, Bakoyiannis CN and Kolvenbach R: Hybrid treatment of common carotid artery occlusion with ring-stripper endarterectomy plus stenting. J Vasc Surg 46: 135-139, 2007.

101.Bozzay J, Broce M and Mousa AY: Hybrid Treatment of Extracranial Carotid Artery Disease. Vasc Endovascular Surg 51: 373-376, 2017.

102.Xu RW, Liu P, Fan XQ, Wang Q, Zhang JB and Ye ZD: Feasibility and Safety of Simultaneous Carotid Endarterectomy and Carotid Stenting for Bilateral Carotid Stenosis: A Single-Center Experience using a Hybrid Procedure. Ann Vasc Surg 33: $138-143,2016$

103. Nussbaum ES and Erickson DL: Extracranial-intracranial bypass for ischemic cerebrovascular disease refractory to maximal medical therapy. Neurosurgery 46: 37-42; discussion 42-33, 2000.

104. EC/IC Bypass Study Group: Failure of extracranial-intracranial arterial bypass to reduce the risk of ischemic stroke. Results of an international randomized trial. N Engl J Med 313: 1191-1200, 1985.

105. Carlson AP, Yonas H, Chang YF and Nemoto EM: Failure of cerebral hemodynamic selection in general or of specific positron emission tomography methodology?: Carotid Occlusion Surgery Study (COSS). Stroke 42: 3637-3639, 2011.

106. Reynolds MR, Derdeyn CP, Grubb RL Jr, Powers WJ and Zipfel GJ: Extracranial-intracranial bypass for ischemic cerebrovascular disease: What have we learned from the Carotid Occlusion Surgery Study? Neurosurg Focus 36: E9, 2014.

107. Kallenberg K, Rühlmann J, Baudewig J, Larsen J, Gröschel S, Dechent P, Kastrup A and Knauth M: Analysis of reserve capacity and subsequent stenting in a case of subacute occlusion of the internal carotid artery. Clin Neuroradiol 23: 225-229, 2013.

108. Hasegawa H, Inoue T, Tamura A and Saito I: Emergent intracranial surgical embolectomy in conjunction with carotid endarterectomy for acute internal carotid artery terminus embolic occlusion and tandem occlusion of the cervical carotic artery due to plaque rupture. J Neurosurg 122: 939-947, 2015.

109. Reichmann BL, Hellings WE, van der Worp HB, Algra A, Brown MM, Mali WP, Moll FL and de Borst GJ: Flow velocities in the external carotid artery following carotid revascularization Eur J Vasc Endovasc Surg 46: 411-417, 2013
110. Xu B, Liu R, Jiao L and Yu J: Carotid endarterectomy for in-stent restenosis: A case report and literature review. Biomed Rep 7: 128-132, 2017.

111. Morino Y, Abe M, Morimoto T, Kimura T, Hayashi Y, Muramatsu T, Ochiai M, Noguchi Y, Kato K, Shibata Y, et al; J-CTO Registry Investigators: Predicting successful guidewire crossing through chronic total occlusion of native coronary lesions within 30 minutes: The J-CTO (Multicenter CTO Registry in Japan) score as a difficulty grading and time assessment tool. JACC Cardiovasc Interv 4: 213-221, 2011.

112. Frenkel MB, Renfrow JJ, Singh J, Garg N and Wolfe SQ: Combined interventional and surgical treatment of tandem middle cerebral artery embolus and internal carotid artery occlusion: Case report. J Neurosurg: Nov 17, 2017 (Epub ahead of print).

113. Malhotra K, Goyal N and Tsivgoulis G: Internal Carotid Artery Occlusion: Pathophysiology, Diagnosis, and Management. Curr Atheroscler Rep 19: 41, 2017.

114. Bigliardi G, Dell'Acqua ML, Vallone S, Barbi F, Pentore R, Picchetto L, Carpeggiani P, Nichelli P and Zini A: 'Opening the Unopenable': Endovascular Treatment in a Patient with Three Months' Internal Carotid Artery Occlusion and Hemispheric Symptomatic Hypoperfusion. J Stroke Cerebrovasc Dis 25: 2016-2018, 2016.

115. John S, Hazaa W, Uchino K and Hussain MS: Timeline of blood pressure changes after intra-arterial therapy for acute ischemic stroke based on recanalization status. J Neurointerv Surg 9: 455-458, 2017.

116. Kobayashi N, Miyachi S, Hattori K, Tanasawa T, Okada T, Endo $\mathrm{O}$ and Yamamoto N: Carotid angioplasty with stenting for chronic internal carotid artery occlusion: Technical note. Neuroradiology 48: 847-851, 2006.

117. Lin MS, Chiu MJ, Wu YW, Huang CC, Chao CC, Chen YH, Lin HJ, Li HY, Chen YF, Lin LC, et al: Neurocognitive improvement after carotid artery stenting in patients with chronic internal carotid artery occlusion and cerebral ischemia. Stroke 42: 2850-2854, 2011.

118. Huang CC, Chen YH, Lin MS, Lin CH, Li HY, Chiu MJ, Chao CC, Wu YW, Chen YF, Lee JK, et al: Association of the recovery of objective abnormal cerebral perfusion with neurocognitive improvement after carotid revascularization. J Am Coll Cardiol 61: 2503-2509, 2013.

This work is licensed under a Creative Commons Attribution-NonCommercial-NoDerivatives 4.0 International (CC BY-NC-ND 4.0) License. 